\title{
Ferramenta Educacional de Tecnologia Assistiva para o Ensino e Prática da Matemática Social de Jovens e Adultos com Deficiência Intelectual
}

\author{
Wilson Henrique Veneziano ${ }^{1}$, Maraísa Helena Borges Estevão Pereira ${ }^{2}$, Lucas \\ Santiago Spíndola Thomaz ${ }^{1}$, Thales Eduardo Gomes Moreira ${ }^{1}$, Neuza Meller ${ }^{3}$ \\ ${ }^{1}$ Universidade de Brasília (UnB) - Departamento de Ciência da Computação \\ Caixa postal 4466 - 70910-900 - Brasília/DF - Brasil \\ ${ }^{2}$ Secretaria de Estado de Educação do Distrito Federal - Brasília/DF \\ ${ }^{3}$ Universidade de Brasília (UnB) - Canal Universitário UnBTV - Brasília/DF \\ wilsonhedunb.br
}

\begin{abstract}
Resumo. Este trabalho expõe as várias etapas da construção de um software educacional de apoio ao ensino de conteúdos básicos da Matemática, aplicada com critérios adaptados de funcionalidade úteis ao cotidiano de jovens e adultos com deficiência intelectual. São trabalhadas situações em que é necessária a utilização de operações concretas, como fazer compras em lojas comerciais e utilizar relógio digital para controle de compromissos. O software dispõe de recursos multimídia que visam facilitar a interação com o estudante e também motivar o mesmo. Os resultados do processo de validação realizado em escolas mostraram que o software é uma ferramenta de ensino útil e eficaz, que complementa o trabalho pedagógico já desenvolvido pelos professores.
\end{abstract}

\begin{abstract}
This paper describes the various stages of building an educational tool to support the mathematics teaching applied to daily life of young people and adults with intellectual disability. The objectives are to increase the autonomy of persons with intellectual disability in daily activities when they need to use the reasoning logical-mathematical, such as grocery shopping and they use the digital clock to have the notion of time and period. The software has multimedia features designed to facilitate student interaction and also motivate him. The results of the validation process carried out in schools with students with intellectual disability showed that the software is a useful and effective teaching tool.
\end{abstract}

\section{Introdução}

A pessoa com deficiência intelectual pode vivenciar situações de discriminação e preconceito na sociedade. Muitas vezes essas pessoas são taxadas de incapazes baseando-se na sua capacidade cognitiva e desenvolvimento biopsicossocial. No Brasil, a Lei de Diretrizes e Bases da Educação Nacional [Brasil 1996] garantiu o direito dos estudantes com necessidades educacionais especiais à educação, estabelecendo em seu Artigo 88 que para integrá-los na comunidade esses estudantes deveriam enquadrar-se, dentro do possível, no sistema geral de educação. Isso foi corroborado pelo artigo $\mathrm{n}^{\circ} 8$ 
V Congresso Brasileiro de Informática na Educação (CBIE 2016)

Anais do XXVII Simpósio Brasileiro de Informática na Educação (SBIE 2016)

da Lei Brasileira de Inclusão da Pessoa com Deficiência (Estatuto da Pessoa com Deficiência) [Brasil 2015].

Para Tezani [2004], a ideia da inclusão está calcada no princípio da igualdade e diversidade. Além disso, fundamenta-se na concepção de educação de qualidade para todos, respeitando a diversidade dos estudantes e realizando o atendimento às suas necessidades educacionais. Isso implica adaptações diante das necessidades individuais de aprendizagem de cada estudante.

Com a evolução do conhecimento, o aprender exige novas formas de construir conhecimentos e se constitui numa exigência social, sendo indispensável para o desenvolvimento pessoal, profissional e, consequentemente, econômico das pessoas. Os conhecimentos matemáticos sofrem diretamente o efeito dessa evolução. Atualmente, a Matemática pode ser aceita tanto como ciência formal e criteriosa, como também, um conjunto de habilidades práticas necessárias à sobrevivência. Há, portanto duas formas de conhecimento matemático, conforme D'Ambrosio [2005] constatou ao estudar a história da Matemática, as quais seriam: a Matemática formal, ensinada nas escolas, e a Matemática informal, praticada por grupos culturais delimitados.

$\mathrm{Na}$ vida cotidiana, Matemática informal é parte da atividade das pessoas, presente desde o ato mais corriqueiro de compra e venda. Para Freire [1997], o ato de ensinar "não é a simples transmissão do conhecimento em torno do objeto ou do conteúdo. Transmissão que se faz muito mais através da pura descrição do conceito do objeto a ser mecanicamente memorizado pelos estudantes". O estudante não se defronta com saberes apenas na escola, no ato da docência, mas em toda a relação com o mundo que o cerca. A partir desta concepção, é possível aceitar e valorizar a importância das experiências informais, que se manifestam em diversas situações cotidianas.

Tendo em vista o apoio ao processo de ensino de pessoas com deficiência intelectual, com a finalidade de melhor inclúi-los na sua comunidade local e estender a funcionalidade social da matemática, foi desenvolvido um software educacional para colaborar com o ensino de conteúdos básicos do currículo escolar e a prática de atividades pedagógicas com aplicabilidade para o dia a dia desses estudantes.

Especificamente no campo da educação de estudantes com deficiência intelectual, não existia, até o ano de 2014, no mercado brasileiro, um software adequado como ferramenta para o ensino da matemática utilizada no dia a dia de jovens e adultos com deficiência intelectual. Este software não pode ser infantilizado e precisa ser adequado às necessidades específicas deste público. $\mathrm{O}$ aplicativo desenvolvido neste trabalho contribui para o aumento da oferta de ferramentas computacionais na área educacional, uma vez que os poucos aplicativos que existem são focados no público infantil.

Para o projeto, cujo produto é relatado neste artigo, traçou-se o objetivo de construir um software educacional gratuito que serve como ferramenta complementar no processo de ensino da matemática e prática cotidiana de jovens e adultos com deficiência intelectual.

\section{Metodologia}

Para o desenvolvimento deste trabalho, foi utilizada consulta a diversas bibliografias e bases de dados. Foram percorridas as seguintes etapas, até que fosse obtido o software: 
V Congresso Brasileiro de Informática na Educação (CBIE 2016)

Anais do XXVII Simpósio Brasileiro de Informática na Educação (SBIE 2016)

estudo acerca da deficiência intelectual e da aplicação matemática ao cotidiano de jovens e adultos com deficiência intelectual, entrevistas com professores especialistas a fim de conhecer o perfil do público alvo e especificar as necessidades do software, desenvolvimento de software, validação do software em escolas públicas, avaliação dos resultados, ajustes no software, decorrentes das avaliações realizadas.

\subsection{Matemática no Cotidiano da Pessoa com Deficiência Intelectual}

A Matemática faz parte da vida de todas as pessoas e desempenha um papel decisivo pelo fato de permitir resolver problemas do cotidiano. Algumas pessoas com deficiência intelectual podem apresentar dificuldades em relação à aplicação da Matemática em seu cotidiano, pois estes, em alguns casos, não conseguem adquirir as noções básicas para a aprendizagem desta disciplina devido às limitações próprias da deficiência $\mathrm{e}$ principalmente por falta de experiências vivenciadas, tendo consequentemente dificuldades para efetuar as necessárias construções lógicas.

A Matemática ensinada para o estudante com deficiência intelectual é a mesma ensinada para qualquer estudante, o que difere, no entanto, são os recursos de acessibilidade que este estudante necessitará para ter acesso a esta área do conhecimento, haja vista sua limitação cognitiva. Assim, na tentativa de tirar o estudante com deficiência intelectual de uma condição passiva diante do conhecimento, buscou-se ensinar ao estudante o uso de ferramentas que auxiliam realizar tarefas do cotidiano. É o caso da calculadora, que para esse público específico, pode ser adaptada e transformar-se em um produto de tecnologia assistiva, contribuindo para o acesso do estudante com deficiência intelectual à vivência de alguns conceitos importantes para $o$ dia a dia. Por exemplo, cálculo de dinheiro e operações fundamentais. O objetivo é propiciar ao estudante o conhecimento da Matemática prática e útil ao seu cotidiano.

\subsection{Desenvolvimento do Software}

Com relação ao processo de software, que é o conjunto de atividades de produção de um software, optou-se pelo desenvolvimento em Modelo Incremental [Pressman 2006], que traz como benefícios: a entrega de incrementos iniciais com o intuito de ganhar experiência e obtenção de informações sobre incrementos posteriores, os clientes não precisam esperar até a entrega do sistema para se beneficiarem dele, existe um risco menor de falha geral do projeto, como os serviços de prioridade alta são entregues primeiros é inevitável que eles recebam mais testes, diminuindo a probabilidade de encontrar falhas nas partes mais importantes do sistema.

Com referência à escolha de uma ferramenta de desenvolvimento, foi necessário usar uma linguagem que favorecesse a utilização de recursos multimídia, que foram muito utilizados no projeto, bem como facilitasse a comunicação com a Internet para permitir o acréscimo de recursos deste tipo no futuro. Também se levou em conta os custos de licença, procurando soluções gratuitas.

Após diversas análises de viabilidade, optou-se pelo Adobe Flash, que é uma plataforma de desenvolvimento muito utilizada em aplicações web. Contudo, também pode ser utilizada para o desenvolvimento de software stand-alone. Ele conta com diversas ferramentas de desenvolvimento produzidas pela Adobe e também com a runtime multiplataforma Flash Player, amplamente difundida em computadores pessoais. Os programas para a plataforma Flash são desenvolvidos na linguagem de 
V Congresso Brasileiro de Informática na Educação (CBIE 2016)

Anais do XXVII Simpósio Brasileiro de Informática na Educação (SBIE 2016)

programação ActionScript, que é uma linguagem orientada a objetos derivada do mesmo padrão que a linguagem JavaScript, o ECMAScript. O Flex SDK, que contém um compilador para ActionScript, é disponibilizado sem custos em duas versões: uma open-source e a outra proprietária com pacotes adicionais. Ambos os SDKs podem ser utilizados em conjunto com ferramentas de desenvolvimento gratuitas como a IDE Eclipse ou a IDE FlashDevelop.

\section{O Software Desenvolvido}

O software foi desenvolvido ao longo do ano de 2014. A primeira versão opera nos sistemas operacionais Microsoft Windows e Linux Educacional. Posteriormente, foi desenvolvida uma versão adaptada para tablets com Android. A seguir, serão apresentados os requisitos educacionais e algumas das lições trabalhadas no software.

\subsection{Requisitos Educacionais}

Os requisitos educacionais que estão envolvidos no software foram especificados principalmente por meio de entrevistas com professores especialistas que atuam na Secretaria de Estado de Educação do Distrito Federal. É importante ressaltar que para as atividades desenvolvidas nesse projeto, foi considerado que os estudantes já possuíam o conhecimento dos números de 0 a 9 , pois esses conceitos foram trabalhados no software Participar [Veneziano 2013]. Alguns dos requisitos educacionais levantados estão listados a seguir:

- Em todas as atividades os estudantes devem interagir de alguma forma, visando atrair a atenção do estudante na atividade proposta. Em alguns momentos são dadas dicas das respostas para que o mesmo possa acertar com mais facilidade;

- O uso de teclado virtual para facilitar a digitação e ao mesmo tempo aumentar o grau de interatividade durante o uso do software;

- As imagens utilizadas nos exercícios foram selecionadas de forma a serem significativas para os estudantes. Elas devem estar presentes no cotidiano social dos estudantes;

- Todas as quantidades foram representadas por imagens reais, visando familiarizar e colaborar na transposição para a realidade concreta. As imagens reais também ajudam a aproximar ainda mais o software ao cotidiano social do estudante;

- As imagens devem ser posicionadas verticalmente ou horizontalmente, evitando a diagonal, pois alguns estudantes podem apresentar dificuldades em observar os objetos quando os mesmos não estão "em pé "ou" deitados";

- No intuito de que o estudante se aproxime e se motive com a ferramenta educacional, foram gravados vídeos com atores com síndrome de Down, e que conduzam e o auxiliem nas tarefas propostas.

\subsection{Visão Geral do Software}

Na tela inicial do programa, a tela de "Boas-vindas", o usuário é acolhido e a ele é apresentada uma visão geral do programa. Ao clicar em 'Início' o usuário acessa o menu principal, onde ele poderá escolher uma das três lições disponíveis: Números, 
V Congresso Brasileiro de Informática na Educação (CBIE 2016)

Anais do XXVII Simpósio Brasileiro de Informática na Educação (SBIE 2016)

Horas e Dinheiro. O teclado virtual, presente em algumas atividades do programa, é um recurso didático desenvolvido com adaptações necessárias para simplificar a visualização do conteúdo pelo estudante. Ele simula o teclado de um computador.

\subsection{Lição Números}

A Lição Números possui diferentes atividades para o aprendizado dos números: como conhecimento gráfico e escrito e representação de quantidades, reconhecimento, no teclado, dos símbolos utilizados nas operações matemáticas e a realização de operações matemáticas de adição e subtração.

\subsubsection{Atividade Numerais}

A atividade Numerais apresenta os números de 0 a 9 para que seja escolhido um número a ser estudado. Após a escolha de um número, é apresentado ao estudante um quadro com figuras que representam a quantidade do número escolhido e o intuito da atividade é que o estudante digite corretamente o número por extenso (Figura 1a). Após a resolução dessa atividade é apresentada uma sequência de atividades que mostram figuras com a mesma quantidade do número escolhido, para que o estudante conte as figuras e digite o número que representa essa quantidade (Figura 1b).

\subsection{Lição Horas}

A lição Horas possui três tipos de atividades: Relógio, Turno e Horas. A atividade relógio serve para o conhecimento e manuseio de um relógio (Figura 2), durante toda a atividade foi utilizado o relógio digital simples e básico, que nesse caso pode ser conceituado como uma tecnologia assistiva, para traduzir com mais facilidade a representação das horas e minutos. Com isso, são suprimidos os marcadores de segundos, visto que o mais importante é a aplicabilidade social das horas em situações cotidianas concretas e funcionais, como apresentar o horário da medicação. $\mathrm{Na}$ atividade Turno o estudante relacionará as atividades que ele faz no dia a dia com os turnos: manhã, tarde e noite. Na atividade Horas o estudante colocará no relógio as horas de acordo com as atividades praticadas por ele em seu cotidiano.
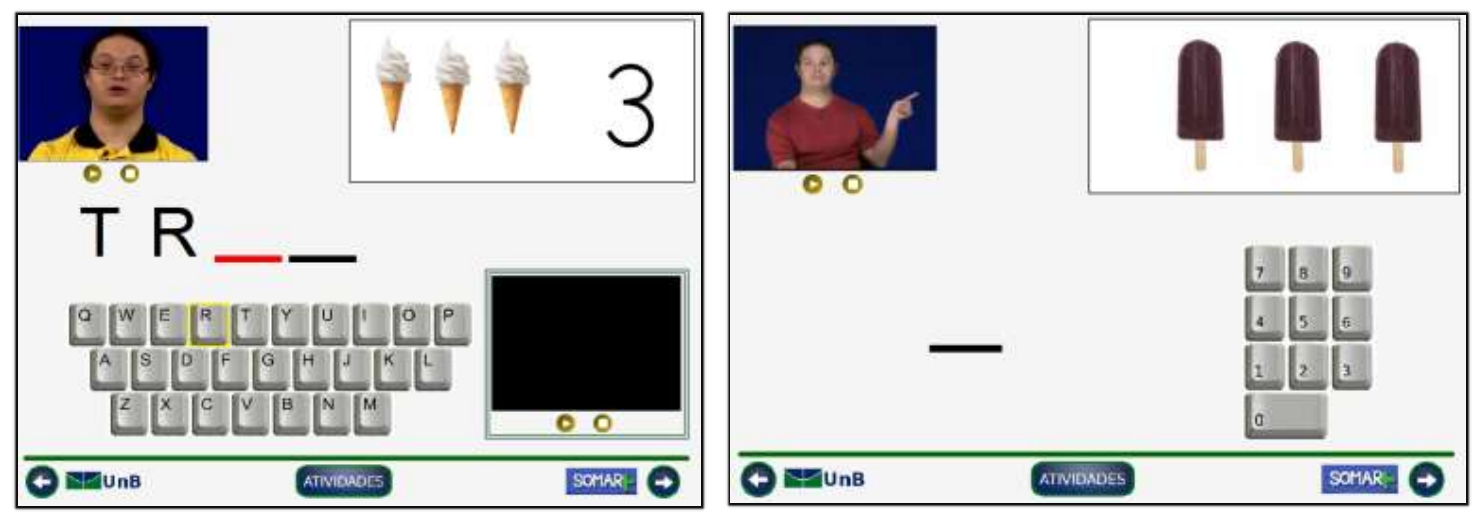

Figura 1: Atividade Numerais. a) Escrita do número por extenso. b) Digitação do quantitativo. 
V Congresso Brasileiro de Informática na Educação (CBIE 2016)

Anais do XXVII Simpósio Brasileiro de Informática na Educação (SBIE 2016)

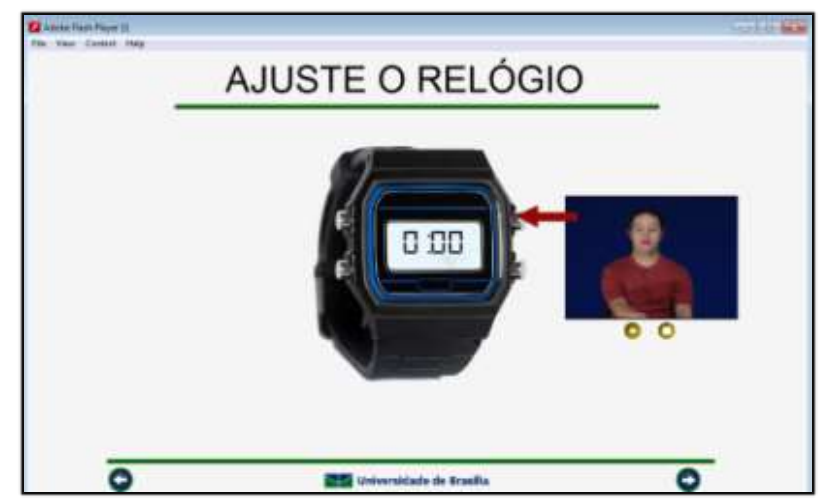

Figura 2: Lição Horas - relógio digital.

\subsection{Lição Dinheiro}

A lição Dinheiro possui diversas atividades para reconhecimento das cédulas e das moedas e do símbolo Real (R\$). As outras atividades são para trabalhar a aplicação do dinheiro no dia a dia das pessoas, como pegar um ônibus ou ir ao mercado, à farmácia ou à padaria fazer compras.

\subsubsection{Atividade Ônibus}

A atividade Ônibus é utilizada para que o estudante possa praticar situações que envolvem troco de dinheiro e desenvolver a capacidade de repetição sobre como é feito o pagamento de uma passagem. É exibido o preço da passagem e o estudante deve escolher entre as notas que estão na carteira qual é suficiente para pagar a passagem (Figura 3a). Também nessa atividade o estudante terá a oportunidade de verificar se para o valor que ele pagou existe um troco, caso em que ele deverá pegar o troco e guardá-lo na carteira (Figura 3b).
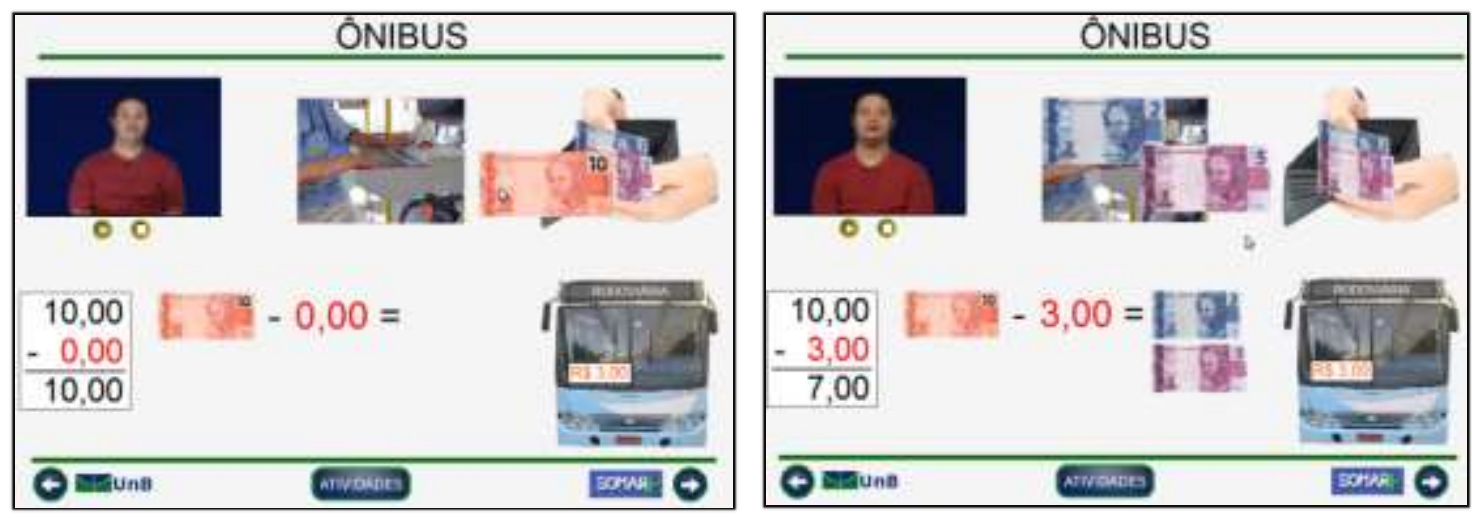

Figura 3: Atividade Ônibus. a) Pagar passagem de ônibus. b) Pegar o troco.

\subsubsection{Atividade Compras}

A atividade Compras é uma simulação de como são feitas as compras. A atividade é dividia em três diferentes situações: Supermercado, Farmácia e Padaria. Para realizar alguma das atividades, em primeiro lugar, o estudante ou professor escolherá um valor para gastar entre $\mathrm{R} \$ 10,00, \mathrm{R} \$ 20,00$ ou $\mathrm{R} \$ 50,00$. Em seguida, será apresentada ao estudante uma prateleira com produtos, de acordo com o lugar escolhido para realizar as compras (Figura 4a). 
V Congresso Brasileiro de Informática na Educação (CBIE 2016)

Anais do XXVII Simpósio Brasileiro de Informática na Educação (SBIE 2016)

Como exemplo, temos o Supermercado, o estudante deverá escolher os produtos e colocá-los no carrinho de compras.

Caso o valor total dos produtos selecionados ultrapasse o valor escolhido para gastar, haverá uma instrução para o estudante retirar um produto. Caso contrário, ele será direcionado ao caixa para efetuar o pagamento (Figura 4b). No caixa, o estudante terá que arrastar a nota para a caixa registradora. Se o valor utilizado para pagar for maior que o valor da compra, o caixa devolverá o troco e o estudante deverá guardá-lo na carteira para finalizar a compra. O software excuta com precisão os movimentos de "arrastar", evitando a produção de fadiga por parte do estudante. Ao fim da atividade é exibido um cupom fiscal da compra, para o estudante conferir os produtos comprados e familiarizar-se com a situação concreta de receber um comprovante de pagamento.
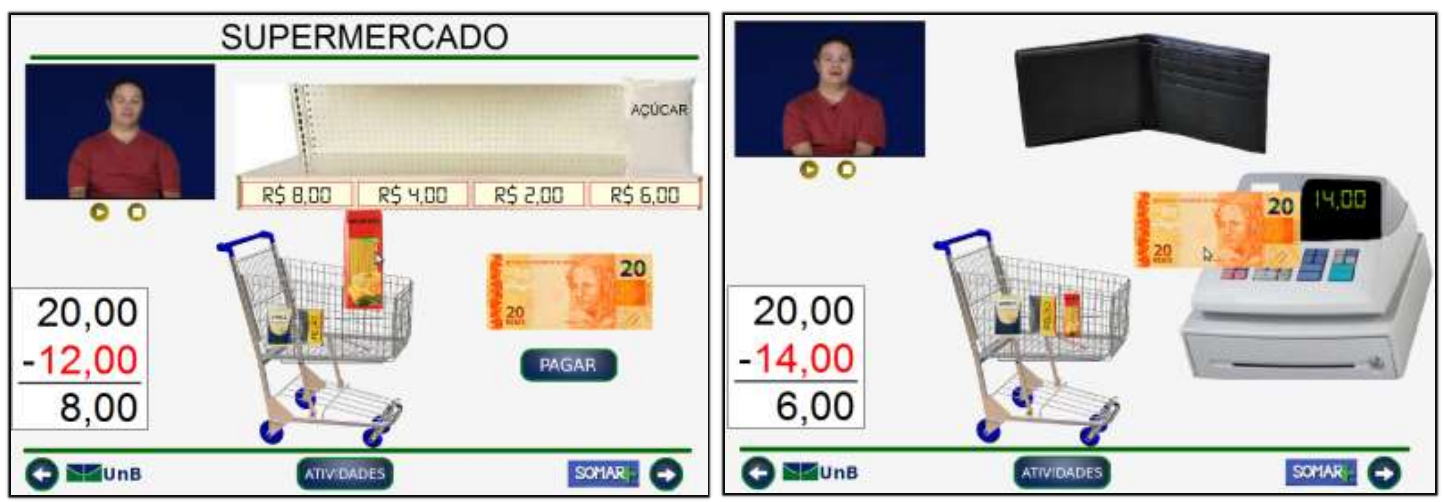

Figura 4: Atividade Compras. a) Escolher produtos. b) Pagar as compras.

\subsection{Lição Calculadora}

$\mathrm{Na}$ atividade Calculadora o intuito é ensinar o estudante a manusear uma calculadora adaptada, como ferramenta funcional, a fim de trazê-lo para mais perto da realidade e tornar o aprendizado mais agradável e simplificado, aplicado ao cotidiano. Ressalta-se a importância de utilizar esta ferramenta como um objeto social, não sendo algo vergonhoso, pois que ela existe justamente para nos ajudar no dia a dia.

$\mathrm{Na}$ atividade Dinheiro o estudante vai aprender a digitar o valor de uma nota na calculadora e, em seguida, fará a soma, na calculadora, do valor de duas notas. $\mathrm{Na}$ atividade Produto o estudante vai aprender, dado o preço de um produto, a digitá-lo na calculadora. E em seguida o estudante fará a soma, na calculadora, do valor de dois produtos. Na atividade Troco o estudante vai aprender a calcular o troco de uma compra (Figura 5). Primeiro, o estudante somará dois produtos e, em seguida, terá que calcular a diferença entre o valor de uma nota e valor total dos dois produtos, somados anteriormente. 


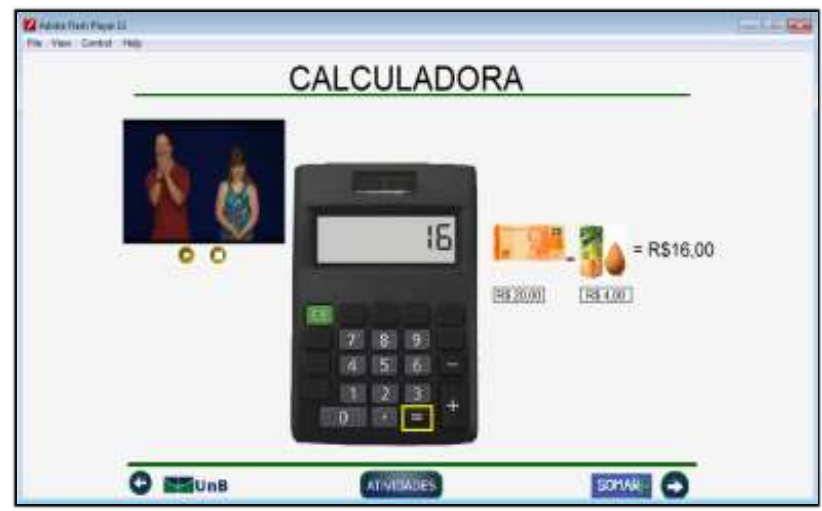

Figura 5: Utilizando a calculadora para calcular o troco de dinheiro.

\section{O Processo de Validação}

No intuito de assegurar que o software atendesse às necessidades de uma ferramenta pedagógica complementar mais condizente com público atendido (jovens e adultos com deficiência intelectual), o aplicativo foi submetido a professores especialistas de escolas da rede pública, bem com a seus estudantes para validação.

Basicamente três dinâmicas de abordagem foram adotadas: foco no professor, foco no estudante e uma terceira que relaciona a interação estudante/ professor/software. $\mathrm{Na}$ primeira forma de abordagem o software era apresentado unicamente ao professor. Nessa ocasião pontuavam-se os aspectos relevantes, sugerindo o acréscimo/retirada de funcionalidades ou elementos que escapavam ao propósito educacional. Nas ocasiões onde o foco da validação era diretamente o estudante, observaram-se itens como acessibilidade, facilidade de uso e motivação ao usar o software. Na abordagem que relaciona estudante, professor e software, a perspectiva de análise esteve voltada ao levantamento de sugestões de uso. Assim, foi possível identificar maneiras de associar o aplicativo às atividades pedagógicas já comumente utilizadas pelos professores. Essas abordagens foram intercaladas ao longo do processo de validação, aplicando-se uma ou outra conforme necessário e em momentos oportunos.

A ferramenta educacional em tela foi disponibilizada para testes em três escolas do Distrito Federal. Durante o processo de validação nas escolas foi dado aos professores um formulário para avaliação do programa. $\mathrm{O}$ formulário foi divido em três dimensões para avaliação: os critérios pedagógicos, a interface e o conteúdo. Cada dimensão foi divida em vários itens que podem ser classificados em: sim, parcialmente ou não. "Sim" quer dizer que o software atende o quesito proposto, "parcialmente" quer dizer que o software atende parcialmente o quesito e "não" quer dizer que o software não atende o quesito. Também foi disponibilizado no formulário um campo para que os professores pudessem escrever algumas observações sobre o software. Com isso, foram feitos os ajustes, a fim de torná-lo mais eficaz no ensino da Matemática voltada para o cotidiano dos estudantes com deficiência intelectual. Ao final do processo de validação, todos os itens avaliados receberam avaliação positiva por parte dos professores.

\section{Conclusões}

Como resultado deste projeto foi construída uma ferramenta pedagógica de tecnologia assistiva, que é um software educacional gratuito. Ao final do processo de validação desse software, os professores envolvidos nessa atividade relataram que a ferramenta é 
V Congresso Brasileiro de Informática na Educação (CBIE 2016)

Anais do XXVII Simpósio Brasileiro de Informática na Educação (SBIE 2016)

útil e que pode ser associada a outras metodologias de ensino ou atividades pedagógicas que auxiliam no processo de aprendizagem da Matemática aplicada ao cotidiano de jovens e adultos com deficiência intelectual.

O programa foi produzido de forma que os recursos multimídia puderam ser adaptados às atividades pedagógicas, aproximou as atividades à realidade do cotidiano social do estudante, utilizou recursos motivacionais e de interatividade, a fim de tornar as atividades mais atrativas e interessantes ao estudante, proporcionando-lhe outros desafios pedagógicos. A organização lógica do conteúdo pedagógico foi apresentada de maneira simplificada, adequando o software ao conteúdo nele trabalhado.

Esse software é uma ferramenta para ser utilizada sob supervisão de professores especializados no processo de ensino de jovens e adultos com deficiência intelectual. $\mathrm{O}$ programa não tem o objetivo de substituir as ferramentas usuais de ensino e não deve ser utilizado por estudantes sem supervisão de um professor. Ressalta-se que essa ferramenta não é um novo método de ensino, mas sim uma tecnologia assistiva para auxiliar e apoiar o processo de ensino e aprendizagem do jovem e adulto deficiente intelectual.

Destacando os aspectos técnicos computacionais, o software foi todo desenvolvido utilizando ferramentas de código livre ou open-source, é portável e permite a inclusão de novas atividades. Da forma que o software foi projetado, o mesmo pode ser executado, tanto instalado no computador do usuário, quanto na forma web usando um navegador com suporte a animações. As configurações mínimas de hardware, para se executar o programa sem comprometer seu desempenho, não exigem computadores muito sofisticados, a fim de viabilizar a utilização dele em escolas públicas.

O software está disponível, gratuitamente, no sítio www.projetoparticipar.unb.br.

\section{Referências}

Brasil (1996). Lei de Diretrizes e Bases da Educação Nacional, Lei No 9.394/96, atualizada em 8 de maio de 2013 pela Lei no 12.796, de 2013). http://www.planalto.gov.br/ccivil 03/leis/19394.htm.

Brasil (2015). Lei Brasileira de Inclusão da Pessoa com Deficiência (Estatuto da Pessoa com Deficiência), Lei $\mathrm{n}^{\mathrm{o}}$ 13.146, de 06 de julho de 2015. https://www.planalto.gov.br/ccivil 03/ ato2015-2018/2015/lei/113146.htm.

D’Ambrosio, U. (2005). Sociedade, cultura, matemática e seu ensino. Educação e Pesquisa, 31(1):99-120.

Freire, P. (1997). Pedagogia da esperança: um reencontro com a pedagogia do oprimido. ed. Rio de Janeiro: Paz e Terra.

Pressman, R. S. (2006). Engenharia de Software. Mcgraw-Hill Interamericana, 6a ed.

Tezani, T. C. R. (2004). Os caminhos para a construção da escola inclusiva: a relação entre a gestão escolar e o processo de inclusão. Mestrado, Centro de Educação e Ciências Humanas, Universidade Federal de São Carlos. http://www.bdtd.ufscar.br

Veneziano, W. H. et all. (2013). Programa Participar: Software Educacional de Apoio à Alfabetização de Jovens e Adultos com Deficiência Intelectual. In: XXIV Simpósio 
V Congresso Brasileiro de Informática na Educação (CBIE 2016)

Anais do XXVII Simpósio Brasileiro de Informática na Educação (SBIE 2016)

Brasileiro de Informática na Educação (SBIE 2013). http://www.brie.org/pub/index.php/sbie/article/view/2526. 